\title{
Nutrient resorption tightens plant nitrogen and phosphorus coupling and decreases with sulfur deposition as mediated by interannual precipitation in a meadow
}

\section{Xue Feng}

Institute of Applied Ecology, Chinese Academy of Sciences

Ruzhen Wang ( $\nabla$ ruzhenwang@iae.ac.cn )

Institute of Applied Ecology Chinese Academy of Sciences https://orcid.org/0000-0001-8654-6677

Tianpeng Li

Institute of Applied Ecology, Chinese Academy of Sciences

Jiangping Cai

Institute of Applied Ecology, Chinese Academy of Sciences

Heyong Liu

Institute of Applied Ecology, Chinese Academy of Sciences

Bin Wang

Institute of Applied Ecology, Chinese Academy of Sciences

Xiaotao Lü

Institute of Applied Ecology, Chinese Academy of Sciences

Yong Jiang

Institute of Applied Ecology, Chinese Academy of Sciences https://orcid.org/0000-0001-7518-5810

\section{Research Article}

Keywords: Sulfur addition, Soil acidification, Nutrient resorption, Nutrient coupling, Natural precipitation, Meadow grassland

Posted Date: November 8th, 2021

DOI: https://doi.org/10.21203/rs.3.rs-1038511/v1

License: (1) This work is licensed under a Creative Commons Attribution 4.0 International License.

Read Full License 


\section{Abstract \\ Purpose}

Sulfur (S) deposition as a global change issue causes worldwide soil acidification, nutrient mobilization and marked changes in plant nutrition. Here, we investigated how $S$ deposition would affect leaf nutrient resorption and how this effect varies with yearly fluctuations in precipitation.

\section{Methods}

In a semiarid meadow exposed to $S$ addition, we measured nitrogen $(N)$, phosphorus $(P)$ and $S$ concentrations in green and senescent leaves of a grass and a sedge and calculated nutrient resorption efficiencies (NuRE) across two years with contrasting precipitation (13\% higher and $27 \%$ lower than longterm mean annual precipitation).

\section{Results}

Concentrations of $\mathrm{N}, \mathrm{P}$, and $\mathrm{S}$ in green and senescent leaves generally increased with $\mathrm{S}$ addition across the two years, with the exception of $\mathrm{N}$ and $\mathrm{P}$ concentrations in green leaves of the grass that showed no response or even decreased with $\mathrm{S}$ addition. The coupling relationships between $\mathrm{N}$ and $\mathrm{P}$ concentrations showed interannual variations and tightened by nutrient resorption, as evidenced by stronger $\mathrm{N}$ and $\mathrm{P}$ correlations in senescent leaves than in green leaves in the wet year. Leaf NuRE convergently decreased with $S$ addition across the two years congruent with soil acidification and increased soil N, P and S availability, while NuRE was higher in the wet year due to lower soil nutrient availability herein.

\section{Conclusions}

This study provides new evidence on the role of nutrient resorption in tightening stoichiometric N:P relationships, and a three-dimensional feedback framework that plant nutrient resorption was favored by higher precipitation to sharpen its tradeoff with soil nutrient availability.

\section{Introduction}

Nutrient resorption is a key physiological process for senescing plants to conserve their nutrients, particularly in nutrient-poor habitats (Aerts 1996; Brant and Chen 2015; Drenovsky et al. 2019; Lü et al. 2012). Based on global estimates, about half of foliar $N$ and $P$ are resorbed during leaf senescence (Aerts 1996; Killingbeck 1996). The resorbed nutrients are readily available for subsequent plant growth, which makes a species less dependent on soil nutrient supply and thus weakens nutrient competition among plant species (Killingbeck 1996; van Heerwaarden et al. 2003). Moreover, this nutrient resorption process can improve plant nutrient-use efficiency, reduce nutrient loss with litterfall decomposition, and eventually 
increase plant fitness in nutrient-poor environments (Vergutz et al. 2012). Therefore, nutrient resorption is an essential trait that provides an alternative strategy for plants to adapt to drier and warmer climates that substantially impoverish global ecosystems (Berdugo et al. 2020; Ren et al. 2018).

Atmosphere sulfur (S) deposition is a main driver of soil acidification which has been regarded as a global environmental issue (Sullivan and Gadd 2019; Vet et al. 2014). Despite large reductions in S deposition during the last few decades across the world (Dentener et al. 2006), chronic deposition continues to acidify terrestrial surface soils and its legacy effects are substantially influencing ecosystem nutrient cycling (Xiao et al. 2020; Yang et al. 2012). Sulfur-induced soil acidification could inhibit soil nitrification and reduce the ratio of soil $\mathrm{NO}_{3}{ }^{-}$to $\mathrm{NH}_{4}{ }^{+}$by favouring $\mathrm{NH}_{4}{ }^{+}$accumulation, thus unbalancing soil mineral $\mathrm{N}$ pool (Chen et al. 2013; Kemmitt et al. 2005; Pan et al. 2020). Furthermore, soil acidification could increase soil $\mathrm{P}$ availability via exchanging $\mathrm{PO}_{4}{ }^{3-}$ from soil minerals and promoting activity of acid phosphatase (Jaggi et al. 2005). However, this direct S supply would promote soil S availability in a greater degree than that of $\mathrm{N}$ and $\mathrm{P}$. As a result, chronic but continuous $\mathrm{S}$ deposition translates into asynchronous increases in soil $\mathrm{N}, \mathrm{P}$, and $\mathrm{S}$ availability to differentially promote plant nutrient uptake (Brown et al. 2000; Jaggi et al. 2005; Stutter et al. 2004; Wang et al. 2002).

Previous studies simulating $S$ deposition with manipulative $S$ addition found that $S$ addition could enhance $\mathrm{N}$ concentrations in both green leaf and plant litterfall (Wang et al. 2002, 2019), because of synergistic interactions between $\mathrm{N}$ and $\mathrm{S}$ during plant assimilation (Li et al. 2019). Similarly, leaf $P$ concentration increased with $\mathrm{S}$ addition as a response to soil $\mathrm{P}$ mobilization with acidification (Sherman et al. 2006; Singh et al. 2012). Therefore, leaf nutrients (such as N, P, and S) are tightly coupled in nature ecosystems (Ågren et al. 2012; Nazar et al. 2011; Sardans et al. 2012; Tallec et al. 2009). In stressful environmental conditions, however, plants would excessively store some of these nutrients (Chapin et al. 1990; Wang et al. 2021), somewhat leading to the decoupling of plant nutrients (He et al. 2008; Yuan and Chen 2015). However, the $\mathrm{N}$ and $\mathrm{P}$ resorption process can drive these nutrients to be re-coupled in plants (Lü et al. 2016). As such, stoichiometric N:P ratios strongly vary with leaf physiological status and environmental stresses, which may be not feasible to be universally used as a reliable indicator for plant $\mathrm{N}$ and $\mathrm{P}$ limitation (Yan et al. 2017). However, the role of nutrient resorption in driving nutrient coupling under scenarios of $\mathrm{S}$ deposition still remains elusive.

As soil nutrients become more available with atmospheric $S$ deposition, plants may reduce their dependence on nutrient resorption concurred with a decrease in nutrient resorption efficiency (NuRE, Lü et al. 2020; Wright and Westoby 2003; Yuan et al. 2015). This negative link between NuRE and soil nutrient availability as a paradigm has been found in many ecosystems (Lü et al. 2013; Ren et al. 2018; Zong et al. 2018). While these studies on plant NuRE mainly focused on the key growth-limiting nutrients of $\mathrm{N}$ and $P$ (Su et al. 2021), resorption efficiency of another macronutrient $S$ (SRE) is rarely studied and if SRE fits in this 'plant NuRE-soil nutrient availability' paradigm under S-deposition scenarios remains large unknown. 
Plant NuRE is an integrator of the effects from various factors, such as climatic conditions, plant physiological status, and soil resources (Suseela et al. 2015; Yuan et al. 2005). For instance, the negative effects of soil nutrient availability on $\mathrm{N}$ and $\mathrm{P}$ resorption efficiencies were only shown in the wet years instead of the dry years (Ren et al. 2018). This is because drought may slow down internal nutrient transportation within plants or decouple plant-soil interactions (Wang et al. 2021), thus cutting off the above-mentioned 'plant NuRE-soil nutrient availability' feedback loop. Moreover, drought can release plant nutrient-acquisition intensity via shortening plant lifespan under water stress and therefore shows no impact on NuRE (Drenovsky et al. 2019). Because of these complex interactions, studies on temporal variability of nutrient resorption with interannual precipitation are need to achieve a mechanistic understanding of how plant NuRE responding to $S$ deposition.

The meadow steppe in northern China is sensitive to global change (Yang et al. 2012). In the past two decades, atmospheric $S$ deposition rate has doubled in the northeast areas of China due to economic development and energy consumption, even though the average rate across the country decreases (Yu et al. 2017). Sulfur deposition contributed to soil acidification across grassland ecosystems in northern China, with the largest decrease of $0.80 \mathrm{pH}$ units in the meadow steppe (Yang et al. 2012). The influence caused by the $S$ deposition on leaf nutrient resorption is rarely considered in this grassland area. But such information is critical to develop a more comprehensive understanding of the factors regulating nutrient conservation strategies in these grasslands. Therefore, our main aim was to investigate the responses of leaf nutrient concentrations and resorption efficiency of two dominant species to $S$ addition in two contrasting wet and dry years in a meadow steppe. We hypothesized that (1) S addition would increase N, $P$ and $S$ concentrations in both green and senesced leaves with stronger coupling relationships among nutrients in senesced leaves than in green leaves as driven by nutrient resorption; and (2) leaf NuRE would decrease with $S$ addition due to increased soil nutrient availability, but this would mainly show in the wet year instead of the dry year.

\section{Materials And Methods}

Site description and experimental design

The S addition experiment is located in the Erguna Forest-Steppe Ecotone Research Station, Inner Mongolia, China (50¹0' $\mathrm{N}, 119^{\circ} 22^{\prime} \mathrm{E}$; elevation 550-600 m). Mean annual precipitation (MAP) is $363 \mathrm{~mm}$ with about $70 \%$ falling between May and September. Mean annual temperature is $-2.45^{\circ} \mathrm{C}$. The grassland is dominated by Leymus chinensis (perennial grass), Carex duriuscula (sedge), Stipa baicalensis (perennial bunchgrass), which account for almost 75\% of total aboveground biomass. The soil is classified as haplic chernozem according to the IUSS Working Group WRB (2015). The pH of topsoil was 6.8-7.0. No grazing and fertilizer were received prior to this experiment.

The experiment was established in a homogeneous and flat field following a randomized block design, with eight $S$ addition rates $\left(0,1,2,5,10,15,20\right.$ and $50 \mathrm{~g} \mathrm{~S} \mathrm{~m}^{-2}$ year $\left.^{-1}\right)$ randomly assigned into each block. Each treatment had five replicates. Elemental S was added once a year in mid-May since 2017 and 
continued each year. Purified S powder fertilizer (elemental S > 99\%) was weighed and mixed with $200 \mathrm{~g}$ soil, and then spread evenly on the surface of the soil in each plot. Atmospheric $S$ deposition at the site is approximately below $3 \mathrm{~g} \mathrm{~S} \mathrm{~m}^{-2} \mathrm{yr}^{-1}$ (Yu et al. 2017) but is expected to increase due to industrial and transportation development (Yu et al. 2017). The high doses of S addition were much higher than the actual local S deposition level, and the aim is to simulate the long-term and accumulative effects of ecosystem $\mathrm{S}$ enrichment as caused by anthropogenic activities.

Field sampling and laboratory measurements

Plant and soil samples were collected in the second $(410 \mathrm{~mm}, 13 \%$ higher than the MAP) and third year (266 mm, 27\% lower than the MAP; Fig. S1) of S treatments. At least 20 healthy plant individuals of $L$. chinensis and $C$. duriuscula with mature and fully extended green leaves were randomly selected in each plot and homogenized into one composite sample in early August. The senesced leaves were sampled in the same way in early October for the two sampling years. All the collected leaves were oven-dried at $65^{\circ} \mathrm{C}$ for $48 \mathrm{hr}$ to constant weight and then ground with a ball mill for chemical analyses (Retsch M400, Retsch $\mathrm{GmbH}$, Haan, Germany). Leaf N concentration was analyzed with an automatic element analyzer (Vario MACRO cube, Elementar Analysensysteme GmbH, Germany). For total P and S concentrations, $300 \mathrm{mg}$ leaf samples were digested with $\mathrm{HNO}_{3}-\mathrm{HClO}_{4}$ solution and then determined with inductively coupled plasma mass spectrometer (5100 ICP-OES, Perkin Elmer, America).

Calculations and statistical analyses

Nutrient resorption efficiency (NuRE) was quantified as the percentage change of a nutrient in senesced leaves relative to the green leaves using the following equation:

$$
\mathrm{NuRE}=\left(1-\frac{\mathrm{Nu}_{\mathrm{s}}}{\mathrm{Nu}_{\mathrm{g}}}\right) \times \mathrm{MLCF} \times 100 \square
$$

where $N u_{g}$ and $N u_{s}$ are the $\mathrm{N}, \mathrm{P}$ or $\mathrm{S}$ concentration in green and senesced leaves; $M L C F$ is the mass loss correction factor with a value of 0.64 and 0.713 for forbs and graminoids respectively as reported by Vergutz et al. (2012).

Data were tested for normality using the Kolmogorov-Smirnov test before performing ANOVA. Two-way ANOVAs were used to explore the main and interactive effects of $S$ addition and sampling year on nutrient concentrations in green and senesced leaves and NuRE of two dominate species, with block included as a random factor. Regression models were used to quantify relationships between $\mathrm{S}$ addition rates and leaf nutrient characteristics with the best curve-fitting results chosen based on coefficient of correlation. Pearson correlation analysis was used to examine the relationships between soil nutrient availability and leaf nutrient concentrations and NuRE. All these analyses were performed using SPSS16.0 (SPSS Inc., Chicago, USA).

\section{Results}


Responses of plant available soil nutrients and leaf nutrient concentrations to $\mathrm{S}$ addition

Sulfur addition significant decreased soil pH in the two sampling years (Table S1). Soil $\mathrm{NH}_{4}{ }^{+}$was the dominant inorganic $\mathrm{N}$ form compared with $\mathrm{NO}_{3}{ }^{-}$, especially with the increasing S-addition rates. Effects of $\mathrm{S}$ addition on plant available nutrients were similar in the two year, where soil $\mathrm{NH}_{4}{ }^{+}$, available $\mathrm{P}$, and available $\mathrm{S}$ increased but $\mathrm{NO}_{3}{ }^{-}$decreased with $\mathrm{S}$ addition (Table $\mathrm{S} 1$ ).

For L. chinensis, green leaf $\mathrm{N}$ concentration was unaltered in the wet year (i.e., 2018), while it significantly decreased with S addition in the dry year (i.e., 2019) (Fig. 1a). Green leaf P concentration was unaltered in the two years (Fig. 1b). Green leaf $S$ concentration increased significantly with $S$ treatments only in the wet year (Fig. 1c). For $C$. duriuscula, green leaf $\mathrm{N}$ concentration significantly increased by $\mathrm{S}$ addition only in the wet year (Fig. 1d). Green leaf $P$ and $S$ concentrations of $C$. duriuscula increased with $S$ addition in two years (Fig. 1e,f).

Senesced leaf $N, P$, and $S$ concentrations for both $L$. chinensis and $C$. duriuscula increased nonlinearly with $\mathrm{S}$ addition across the two sampling years, except for senescent leaf $\mathrm{N}$ concentration of $C$. duriuscula showing a linear increase in the dry year (Fig. 1g-l).

Coupling relationships between nutrients in green and senesced leaves

The coupling relationships between leaf $\mathrm{N}$ and $\mathrm{P}$ concentrations in senescent leaves of two species were higher than that in green leaves when two years were pooled (Fig. 2a,b vs. Fig. 2c,d). In the wet year, the relationships between leaf $\mathrm{N}$ and $\mathrm{P}$ in senescent leaves were more tightly than that in green leaves (Fig. 2). However, the coupling relationship of $\mathrm{N}$ and $\mathrm{P}$ in senescent leaves was weaker than that in green leaves in the dry year (Fig. 2).

Responses of nutrient resorption efficiency to S addition

For $L$. chinensis, the reductions in leaf NRE, PRE, and SRE were noticeably similar in response to $S$ addition in the dry and wet years (Fig. 3a-C; Table S2). For C. duriuscula, leaf NRE and PRE increased and then decreased with S addition in the wet year (Fig. 3d,e). Leaf NRE in the dry year and SRE in the two years decreased linearly with S addition (Fig. 3d,f; Table S2). For both species, NuRE was significantly higher in the wet year than that in the dry year (Fig. 3; Table S2).

Correlation analyses

Only for L. chinensis, green leaf $\mathrm{N}$ concentration positively correlated with soil $\mathrm{NO}_{3}{ }^{-}$in the dry year 2019. Only for $C$. duriuscula, green leaf $\mathrm{P}$ concentration positively correlated with plant available $\mathrm{P}$ in the wet year 2018. However, green leaf S positively related to plant available $S$ for $L$. chinensis in the wet year and for $C$. duriuscula in the two years (Table S3). 
For both species, leaf NRE and PRE were mostly independent of plant available N and P, except for NRE of C. duriuscula in year of 2018 (Table S4). However, leaf SRE and plant available S concentration was negatively correlated for both species in the two sampling years (Table S4).

\section{Discussion}

Nutrient resorption can decrease plant reliance on soil nutrient pool and substantially influence plant growth, survival and reproduction (Yuan and Chen 2015). Given by the fact that atmospheric S deposition and its related legacy effects (e.g., soil acidification) are still an important environmental issue in the grassland ecosystems of northern China (Yu et al. 2017), information on how S deposition impacts plant nutrient resorption would be helpful in understanding plant community assembly and plant species adaption to global change factors. However, no studies as we know have yet investigated S-deposition effects on leaf NuRE, especially SRE in meadow grasslands, as mediated by interannual precipitation. Therefore this research was the first to concern the coupling of $N, P$, and $S$ concentrations in green versus senescent leaves and their resorption efficiency as affected by $S$ addition and natural precipitation. As expected, we found that $\mathrm{N}$ and $\mathrm{P}$ concentrations were tightly coupled in the senescent leaves in the wet year as mainly driven by higher NuRE. However, NuRE decreased more sharply with S-addition gradient in the dry year than the wet year (Fig. 4), which was contrary to our hypothesis.

Leaf nutrient concentrations in response to $S$ addition with stronger coupling of $N$ and $P$ in senescent versus green leaves

Partially consistent with our first hypothesis, nutrient concentrations mostly increased with $S$ addition for both green and senescent leaves with the exception for green leaf of $L$. chinensis (Fig. 1). Indeed, $L$. chinensis was suggested to stay more homoeostatic than other species (such as Carex korshinskyi) in response to exogenous nutrient addition (Yu et al. 2010). Green leaf N concentration even decreased with

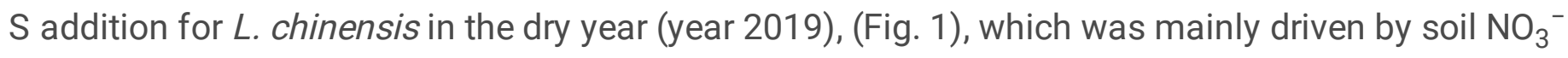
concentration as evidenced by the positive correlation between the two parameters (Table S3). In contrast to $L$. chinensis, green leaf $\mathrm{N}$ concentration of $C$. duriuscula showed an increasing trend with $\mathrm{S}$ treatment, suggesting that the two species possibly have contrasting $\mathrm{N}$ acquisition strategy (Legay et al. 2014).

An increase in soil available P under S-addition induced acidification (Xiao et al. 2020; Table S1) might have accounted for the higher leaf $P$ concentration herein. This was further evidenced by a positive correlation between green leaf $\mathrm{P}$ concentration and plant available $\mathrm{P}$ concentration for $C$. duriuscula in 2018 (Table S3). As expected, leaf S concentration (except for green leaf S concentration of L. chinensis in 2019) increased with the increasing $S$ addition and positively correlated with plant available $S$ (Table S3) due to plant luxury absorption of $S$ (Wang et al. 2002). Furthermore, we found that the leaf $S$ concentration in wet year was significantly lower than that in dry year (Fig. 1i,l), possibly because of higher dilution effects on plant nutrient concentrations or soil $\mathrm{SO}_{4}{ }^{2-}$ leaching in the wet year (Blake-Kalff et al. 2000; Li et al. 2019). Moreover, we found N, P and S in senescent leaves of the two species 
consistently increased with $\mathrm{S}$ addition which would result in higher litter quality, subsequently increasing litter decomposition rates.

Consistent with our first hypothesis, the positive relationship between leaf $\mathrm{N}$ and $\mathrm{P}$ was much stronger in senescent leaves than that in green leaves across the two sampling years when data were pooled (Figs. 2 and 4). However, this stronger relationship in senescent relative to green leaves was only found in the wet year instead of the dry year (Fig. 2a,b vs. Fig. 2c,d). Possibly, variations in interannual environmental conditions, e.g. water availability could show remarkable influences on the coupling of $\mathrm{N}$ and $\mathrm{P}$ in leaves (You et al. 2018; Yuan and Chen 2015). This suggested that nutrient-resorption process could tighten the relationships of leaf $\mathrm{N}$ and $\mathrm{P}$ upon the alleviation of water limitation in this semi-arid ecosystem (Fig. 4; Lü et al. 2016; You et al. 2018). In the dry year, the coupling pattern was inversed as shown by a stronger relationship between $\mathrm{N}$ and $\mathrm{P}$ in the green leaves than that in the senescent ones (Fig. 2). This might be a result of stronger effects from biochemical and metabolic processes in green leaves to couple $\mathrm{N}$ and $\mathrm{P}$ than that from nutrient-resorption process in senescent leaves under plant water stress (Duarte 1992; Rentería et al. 2011). Previous studies also found that drought triggered leaf senescence as a physiological response (Munné-Bosch and Alegre 2004) and resulted in nutrient imbalance and decoupling (Chen et al. 2015). Overall, our results provided new evidence for the role of hydrologic conditions in mediating the coupling relationships between $\mathrm{N}$ and $\mathrm{P}$ in leaves with different physiological conditions under $\mathrm{S}$ addition.

Decreases in NuRE with S addition vary with interannual precipitation

Consistent with our second hypothesis, leaf N, P and S resorption efficiency decreased with S addition (Figs. 3 and 4). Evidences suggested that soil nutrient availability modulated plant nutrient conservation strategies so that plants in nutrient-rich environments tended to have lower resorption efficiency (Yuan and Chen 2015). Along with elemental $\mathrm{S}$ gradient, soil available $\mathrm{N}\left(\right.$ mainly $\mathrm{NH}_{4}{ }^{+}$) increased through inhibiting nitrification (Chen et al. 2013; De Boer and Kowalchuk 2001; Xiao et al. 2020) and available P increased through sulphate replacing phosphate ions from the colloidal surface and/or via organic $P$ mineralization (Jaggi et al. 2005). For $\mathrm{N}$ and $\mathrm{P}$, insignificant correlations between nutrient resorption efficiency and soil nutrient availability for both species (Table S4) suggested that leaf NuRE might be also controlled by other soil characteristics, such as soil moisture and soil pH (Yuan et al. 2005). Similarly, inconsistent relationships between plant nutrient resorption and soil nutrient availability were also found at global scale (Vergutz et al. 2012). This inconsistency could be partly caused by the divergent response of $\mathrm{N}$ and $\mathrm{P}$ resorption efficiencies to nutrient addition in nutrient-rich versus nutrientpoor habitats (Wright and Westoby 2003). Compared to NRE and PRE, SRE was more clearly correlated with plant available S in two species (Table S4), which was directly due to the exogenous supply of plant available $S$ (Kobe et al. 2005). Therefore, our results suggest that plants tend to rely less on nutrient internal cycling when soil nutrient availability increases (Wright and Westoby 2003), but the degree of this decrease of reliance varies among different nutrients. Furthermore, S-induced decreases in nutrient resorption would substantially alter chemical composition of plant tissues and eventually the litter 
decomposition processes and the coupling relationship of above- and belowground nutrient cycling (Suseela and Tharayil 2018).

We also found that the response of NuRE to $S$ addition varied with interannual precipitation with a higher NuRE in the wet year but sharper decreases with increasing $S$ rates in the dry year (Figs. 3 and 4). This may be due to the longer reproductive stage and stand age under lower water stress, when plants have to invest more nutrient and energy on both vegetative growth and reproductive efforts (Brant and Chen 2015). Additionally, enhanced leaching of nutrients from leaves and soils could result in higher NuRE (Lu et al. 2019). Consistently, Ren et al. (2018) suggested that $N$ and $P$ resorption efficiency decreased with nutrient addition in the wet year, but that these effects flattened in the dry year in a desert grassland. However, we can not rule out the possibility that other factors, i.e., plant species characteristics, soil nutrient pool size (Lü et al. 2012), type and amount of S additions (Lü et al. 2013) and habitat type (Kobe et al. 2005) can influence the response of NuRE to $S$ addition. Therefore, the single-dimensional 'plant NuRE-soil nutrient availability' paradigm should be reconsidered as a multifaceted feedback network that nutrient availability is coordinated by other factors (e.g., precipitation in this study) to influence plant NuRE (Fig. 4).

Nevertheless, this flexibility of NuRE in response to temporal variations in precipitation and nutrient availability can shed light on the spatially resource-dependent strategies of plant nutrient use in microscale soil fertility patchiness (Lü et al. 2012). Therefore, the flexible and species-specific NuRE can help explain heterogeneity in species distribution and species turnover with exotic species colonization and native species extinction within plant communities. To our knowledge, the linkages of NuRE with plant species turnover and the consequential community assembly have rarely been tested (Lü et al. 2019). Our study calls for future working investigating the influences of temporal and spatial variations in resources on plant NuRE at both species and community level in order to understand the role of NuRE for evidencing plant community dynamics.

\section{Conclusion}

The study found that two dominant species from the semiarid meadow grassland tended to increase nutrient $(\mathrm{N}, \mathrm{P}$, and $\mathrm{S}$ ) concentrations in leaves but to reduce nutrient resorption efficiency with $\mathrm{S}$ addition during two consecutive years. Leaf $\mathrm{N}$ and $\mathrm{P}$ were more tightly coupled in senescent leaves than that in green leaves averaging across the two years, which could be mainly driven by nutrient resorption. The decrease of leaf NuRE with S addition was possibly due to mobilization of plant available nutrients in soil under acidification. Nutrient resorption was also regulated by interannual precipitation as evidenced by the fact of higher NURE in the wet year and that only leaf SRE was closely correlated with plant available S. Higher NuRE in the wet year suggested enhancement of plant nutrient requirements in less waterlimited conditions, likely derived from longer plant reproductive stage and stand age in such conditions. To our knowledge, the study was the first to reveal the distinct coupling relationships between $\mathrm{N}$ and $\mathrm{P}$ concentrations in green versus senescent leaves and that interannual precipitation substantially modulate the response of nutrient resorption to $S$ deposition. These findings imply the important role of 
nutrient resorption, as a plant-nutrition integrator comprising the influences from multifaceted ecological processes, in affecting plant species competition, plant community assembly, and the associations between above- and below-ground nutrient cycling. Further work is clearly required to establish a linkage between nutrient resorption and plant community dynamics under global change scenarios and to verify the multidimensional feedback network of NuRE responding to global change factors as proposed in the current study.

\section{Declarations}

\section{Author contribution}

YJ designed the study. RW, TL, and HL set up the field experiment and applied fertilizer every year. XF, TL, and JC performed field and laboratory works and data statistical analyses. RW and XL contributed to the interpretation and discussion of the results. XF and RW drafted the manuscript with suggestions from all the co-authors.

\section{Acknowledgments}

The study was financially supported by the National Natural Science Foundation of China (31870441 and 32071563) and the Strategic Priority Research Program of the Chinese Academy of Sciences (XDA23080402). Ruzhen Wang acknowledges the support from Youth Innovation Promotion Association of Chinese Academy of Sciences.

\section{Data availability}

We confirm that, should the manuscript be accepted, the data supporting the results will be archived in Dryad and the data DOI will be included at the end of the article.

\section{References}

Aerts R (1996) Nutrient resorption from senescing leaves of perennials: are there general patterns? J Ecol 84:597-608. https://doi.org/10.2307/2261481

Ågren GI, Wetterstedt JÅM, Billberger MFK (2012) Nutrient limitation on terrestrial plant growth-modeling the interaction between nitrogen and phosphorus. New Phytol 194:953-960.

https://doi.org/10.1111/j.1469-8137.2012.04116.x

Berdugo M, Delgado-Baquerizo M, Soliveres S, Hernández-Clemente R, Zhao Y, Gaitán JJ, Gross N, Saiz H, Maire V, Lehman A (2020) Global ecosystem thresholds driven by aridity. Science 367:787-790.

https://doi.org/10.1126/science.aay5958 
Blake-Kalff MMA, Hawkesford MJ, Zhao F, McGrath SP (2000) Diagnosing sulfur defciency in field-grown oilseed rape (Brassica napus L.) and wheat (Triticum aestivum L.). Plant Soil 225:95-

107.https://doi.org/10.1023/A:1026503812267

Brant AN, Chen HY (2015) Patterns and mechanisms of nutrient resorption in plants. Crit rev Plant Sci 34:471-486. https://doi.org/10.1080/07352689.2015.1078611

Brown L, Scholefield D, Jewkes EC, Preedy N, Wadge K, Butler M (2000) The effect of sulphur application on the efficiency of nitrogen use in two contrasting grassland soils. J Agric Sci 135:131-138.

https://doi.org/10.1017/S0021859699008072

Chapin III FS, Schulze ED, Mooney HA (1990) The ecology and economics of storage in plants. Annu Rev Ecol Syst 21:423-447.

https://doi.org/10.1146/annurev.es.21.110190.002231

Chen D, Lan Z, Bai X, Grace JB, Bai Y (2013) Evidence that acidification-induced declines in plant diversity and productivity are mediated by changes in below-ground communities and soil properties in a semiarid steppe. J Ecol 101:1322-1334. https://doi.org/10.1111/1365-2745.12119

Chen D, Wang S, Xiong B, Cao B, Deng X (2015) Carbon/nitrogen imbalance associated with droughtinduced leaf senescence in sorghum bicolor. PloS ONE 10:e0137026.

https://doi.org/10.1371/journal.pone.0137026

De Boer W, Kowalchuk GA (2001) Nitrification in acid soils: micro-organisms and mechanisms. Soil Biol Biochem 33:853e866.

https://doi.org/10.1016/S0038-0717(00)00247-9

Dentener F, Drevet J, Lamarque JF et al (2006) Nitrogen and sulfur deposition on regional and global scales: A multimodel evaluation. Global Biogeochem Cy 20:GB4003.

https://doi.org/10.1029/2005GB002672

Drenovsky RE, Pietrasiak N, Short TH (2019) Global temporal patterns in plant nutrient resorption plasticity. Global Ecol Biogeogr 28:728-743.

https://doi.org/10.1111/geb.12885

Duarte CM (1992) Nutrient concentration of aquatic plants: patterns across species. Limnol Oceanogr 37:882-889.

https://doi.org/10.4319/lo.1992.37.4.0882 
He J, Wang L, Flynn DF, Wang X, Ma W, Fang J (2008) Leaf nitrogen: phosphorus stoichiometry across Chinese grassland biomes. Oecologia 155:301-310.

https://doi.org/10.1007/s00442-007-0912-y

IUSS Working group WRB. (2015) World Reference Base for soil resources 2014, update 2015, International soil classification system for naming soils and creating legends for soil maps. World Soil Resour Rep No. 106. FAO, Rome.

Jaggi RC, Aulakh MS, Sharma AR (2005) Impacts of elemental S applied under various temperature and moisture regimes on $\mathrm{pH}$ and available $\mathrm{P}$ in acidic, neutral and alkaline soils. Biol Fert Soils 41:52-58.

https://doi.org/10.1007/s00374-004-0792-9

Kemmitt SJ, Wright D, Jones DL (2005) Soil acidification used as a management strategy to reduce nitrate losses from agricultural land. Soil Biol Biochem 37:867-875.

https://doi.org/10.1016/j.soilbio.2004.10.001

Killingbeck KT (1996) Nutrients in senesced leaves: keys to the search for potential resorption and resorption proficiency. Ecology 77:1716-1727.

https://doi.org/10.2307/2265777

Kobe RK, Lepczyk CA, lyer M (2005) Resorption efficiency decreases with increasing green leaf nutrients in a global data set. Ecology 86:2780-2792.

https://doi.org/10.1890/04-1830

Legay N, Personeni E, Slezack-Deschaumes S, Piutti S, Cliquet JB (2014) Grassland species show similar strategies for sulphur and nitrogen acquisition. Plant Soil 375:113-126. https://doi.org/10.1007/s11104013-1949-9

Li N, Yang Y, Wang L, Zhou C, Jing J, Sun X, Tian X (2019) Combined effects of nitrogen and sulfur fertilization on maize growth, physiological traits, $\mathrm{N}$ and $\mathrm{S}$ uptake, and their diagnosis. Field Crop Res 242:107593.

https://doi.org/10.1016/j.fcr.2019.107593

Lu J, Yang M, Liu M, Wang Y, Yang H (2019) Leaf stoichiometry and resorption of N and P in Lucerne at different growth stages under different water supplies. J Plant Nutr 42:501-511. https://doi.org/10.1080/01904167.2019.1567776

Lü X, Freschet GT, Flynn DF, Han X (2012) Plasticity in leaf and stem nutrient resorption proficiency potentially reinforces plant-soil feedbacks and microscale heterogeneity in a semi-arid grassland. $J$ Ecol 100:144-150. 
Lü X, Hou S, Reed SC, Yin J, Hu Y, Wei H, Zhang Z, Yang G, Liu Z, Han X (2020) Nitrogen Enrichment Reduces Nitrogen and Phosphorus Resorption Through Changes to Species Resorption and Plant Community Composition. Ecosystems 24:602-612. https://doi.org/10.1007/s10021-020-00537-0

Lü X, Hu Y, Wolf AA, Han X (2019) Species richness mediates within-species nutrient resorption: Implications for the biodiversity-productivity relationship. J Ecol 107:2346-2352. https://doi.org/10.1111/1365-2745.13180

Lü X, Reed SC, Yu Q, He N, Wang Z, Han X (2013) Convergent responses of nitrogen and phosphorus resorption to nitrogen inputs in a semiarid grassland. Global Change Biol 19:2775-2784. https://doi.org/10.1111/gcb.12235

Lü X, Reed SC, Yu Q, Han X (2016) Nutrient resorption helps drive intra-specific coupling of foliar nitrogen and phosphorus under nutrient-enriched conditions. Plant Soil 398:111-120.

https://doi.org/10.1007/s11104-015-2642-y

Munné-Bosch S, Alegre L (2004) Die and let live: leaf senescence contributes to plant survival under drought stress. Funct Plant Biol 31:203-216.

https://doi.org/10.1071/FP03236

Nazar R, Iqbal N, Masood A, Syeed S, Khan NA (2011) Understanding the significance of sulfur in improving salinity tolerance in plants. Environ Exp Bot 70:80-87.

https://doi.org/10.1016/j.envexpbot.2010.09.011

Pan S, Wang Y, Qiu Y, Chen D, Zhang L, Ye C, Guo H, Zhu W, Chen A, Xu G, Zhang Y, Bai Y, Hu S (2020) Nitrogen-induced acidification, not $\mathrm{N}$-nutrient, dominates suppressive $\mathrm{N}$ effects on arbuscular mycorrhizal fungi. Global Change Biol 26:6568-6580. https://doi.org/10.1111/gcb.15311

Ren H, Kang J, Yuan Z, Xu Z, Han G (2018) Responses of nutrient resorption to warming and nitrogen fertilization in contrasting wet and dry years in a desert grassland. Plant Soil 432:65-73. https://doi.org/10.1007/s11104-018-3775-6

Rentería LY, Jaramillo VJ (2011) Rainfall drives leaf traits and leaf nutrient resorption in a tropical dry forest in Mexico. Oecologia 165:201-211. https://doi.org/10.1007/s00442-010-1704-3

Sardans J, Rivas-Ubach A, Penuelas J (2012) The elemental stoichiometry of aquatic and terrestrial ecosystems and its relationships with organismic lifestyle and ecosystem structure and function: a review and perspectives. Biogeochemistry 111:1-39. https://doi.org/10.1007/s10533-011-9640-9

Sherman J, Fernandez IJ, Norton SA, Ohno T, Rustad LE (2006) Soil aluminum, iron, and phosphorus dynamics in response to long-term experimental nitrogen and sulfur additions at the bear brook 
watershed in maine, USA. Environ Monit Assess 121:421-429. https://doi.org/10.1007/s10661-005-91402

Singh AK, Meena MK, Upadhyaya A (2012) Effect of sulphur and zinc on rice performance and nutrient dynamics in plants and soil of Indo Gangetic plains. J Agric Sci 4:162-170.

https://doi.org/10.5539/jas.v4n11p162

Stutter MI, Alam MS, Langan SJ, Woodin SJ, Smart RP, Cresser MS (2004) The effects of $\mathrm{H}_{2} \mathrm{SO}_{4}$ and $\left(\mathrm{NH}_{4}\right)_{2} \mathrm{SO}_{4}$ treatments on the chemistry of soil drainage water and pine seedlings in forest soil microcosms. Hydrol Earth Syst Sci 8:392-408. https://doi.org/10.5194/hess-8-392-2004

Su Y, Ma X, Gong Y, Li K, Han W, Liu X (2021) Responses and drivers of leaf nutrients and resorption to nitrogen enrichment across northern China's grasslands: A meta-analysis. Catena 199:105110.

https://doi.org/10.1016/j.catena.2020.105110

Sullivan T, Gadd GM (2019) Metal bioavailability and the soil microbiome. Adv Agron 155:79-120. https://doi.org/10.1016/bs.agron.2019.01.004

Suseela V, Tharayil N (2018) Decoupling the direct and indirect effects of climate on plant litter decomposition: Accounting for stress-induced modifications in plant chemistry. Global Change Biol 24:1428-1451. https://doi.org/10.1111/gcb.13923

Suseela V, Tharayil N, Xing BS, Dukes JS (2015) Warming and drought differentially influence the production and resorption of elemental and metabolic nitrogen pools in Q uercus rubra. Global Change Biol 21:4177-4195.

https://doi.org/10.1111/gcb.13033

Tallec T, Diquélou S, Avice JC, Lesuffleur F, Lemauviel-Lavenant S, Cliquet JB, Ourry A (2009) Availability of $\mathrm{N}$ and $\mathrm{S}$ affect nutrient acquisition efficiencies differently by Trifolium repens and Lolium perenne when grown in monoculture or in mixture. Environ Exp Bot 66:309-316.

https://doi.org/10.1016/j.envexpbot.2009.02.002

van Heerwaarden L, Toet S, Aerts R (2003) Current measures of nutrient resorption efficiency lead to a substantial underestimation of real resorption efficiency: facts and solutions. Oikos 101:664-669. https://doi.org/10.1034/j.1600-0706.2003.12351.x

Vergutz L, Manzoni S, Porporato A, Novais R, Jackson R (2012) Global resorption efficiencies and concentrations of carbon and nutrients in leaves of terrestrial plants. Ecol Monogr 82:205-220. https://doi.org/10.1890/11-0416.1 
Vet R, Artz RS, Carou S, Shaw M, Ro CU, Aas W (2014) A global assessment of precipitation chemistry and deposition of sulfur, nitrogen, sea salt, base cations, organic acids, acidity and $\mathrm{pH}$, and phosphorus. Atmos Environ 93:3-100. https://doi.org/10.1016/j.atmosenv.2013.10.060

Wang Q, Kwak JH, Choi WJ, Chang SX (2019) Long-term N and S addition and changed litter chemistry do not affect trembling aspen leaf litter decomposition, elemental composition and enzyme activity in a boreal forest. Environ Pollut 250:143-154. https://doi.org/10.1016/j.envpol.2019.04.007

Wang R, Cresswell T, Johansen MP, Harrison JJ, Jiang Y, Keitel C, Cavagnaro TR, Dijkstra FA (2021) Reallocation of nitrogen and phosphorus from roots drives regrowth of grasses and sedges after defoliation under deficit irrigation and nitrogen enrichment. J Ecol. https://doi.org/10.1111/1365-2745.13778

Wang R, Lü L, Cao Y, Sardans J, Liu H, Li B, Zhang Y, Peñuelas J, Dijkstra FA, Jiang Y (2021) Stability of elemental content correlates with plant resistance to soil impoverishment. Plant Soil. https://doi.org/10.1007/s11104-021-05079-5

Wang S, Wang Y, Schnug E, Haneklaus S, Fleckenstein J (2002) Effects of nitrogen and sulphur fertilization on oats yield, quality and digestibility and nitrogen and sulphur metabolism of sheep in the Inner Mongolia Steppes of China. ～N Nutr Cycling Agroecosyst 62:195-202.

https://doi.org/10.1023/A:1015592423948

Wright IJ, Westoby M (2003) Nutrient concentration, resorption and lifespan: leaf traits of Australian sclerophyll species. Funct Ecol 17:10-19. https://doi.org/10.1046/j.1365-2435.2003.00694.x

Xiao H, Wang B, Lu S, Chen D, Wu Y, Zhu Y, Hu S, Bai Y (2020) Soil acidification reduces the effects of short-term nutrient enrichment on plant and soil biota and their interactions in grasslands. Global Change Biol 26:4626-4637. https://doi.org/10.1111/gcb.15167

Yan Z, Tian D, Han W, Tang Z, Fang J (2017) An assessment on the uncertainty of the nitrogen to phosphorus ratio as a threshold for nutrient limitation in plants. Ann Bot 120:937-942. https://doi.org/10.1093/aob/mcx106

Yang Y, Ji C, Ma W, Wang S, Wang S, Han W, Mohhammat A, Robinson D, Smith P (2012) Significant soil acidification across northern China's grasslands during 1980s-2000s. Global Change Biol 7:2292-2300. https://doi.org/10.1111/j.1365-2486.2012.02694.x

You C, Wu F, Yang W, Xu Z, Tan B, Zhang L, Yue K, Ni X, Li H, Chang C, Fu C (2018) Does foliar nutrient resorption regulate the coupled relationship between nitrogen and phosphorus in plant leaves in response to nitrogen deposition?. Sci Total Environ 645:733-742. https://doi.org/10.1016/j.scitotenv.2018.07.186

Yu H, He N, Wang Q, Zhu J, Gao Y, Zhang Y, Jia Y, Yu G (2017) Development of atmospheric acid deposition in China from the 1990s to the 2010s. Environ Pollut 231:182-190.

https://doi.org/10.1016/j.envpol.2017.08.014

Page 15/21 
Yu Q, Chen Q, Elser JJ, He N, Wu H, Zhang G, Wu J, Bai Y, Han X (2010) Linking stoichiometric homoeostasis with ecosystem structure, functioning and stability. Ecol Lett 13:1390-1399. https://doi.org/10.1111/j.1461-0248.2010.01532.x

Yuan Z, Chen HY (2015) Decoupling of nitrogen and phosphorus in terrestrial plants associated with global changes. Nat Clim Chang 5:465-469. https://doi.org/10.1038/nclimate2549

Yuan Z, Li L, Han X, Huang J, Jiang G, Wan S (2005) Soil characteristics and nitrogen resorption in Stipa krylovii native to northern China. Plant Soil 273:257-268. https://doi.org/10.1007/s11104-004-7941-7

Zong N, Shi P, Chai X (2018) Effects of warming and nitrogen addition on nutrient resorption efficiency in an alpine meadow on the northern Tibetan Plateau. Soil Soil Sci Plant Nutr 64:482-490.

https://doi.org/10.1080/00380768.2018.1467727

\section{Figures}



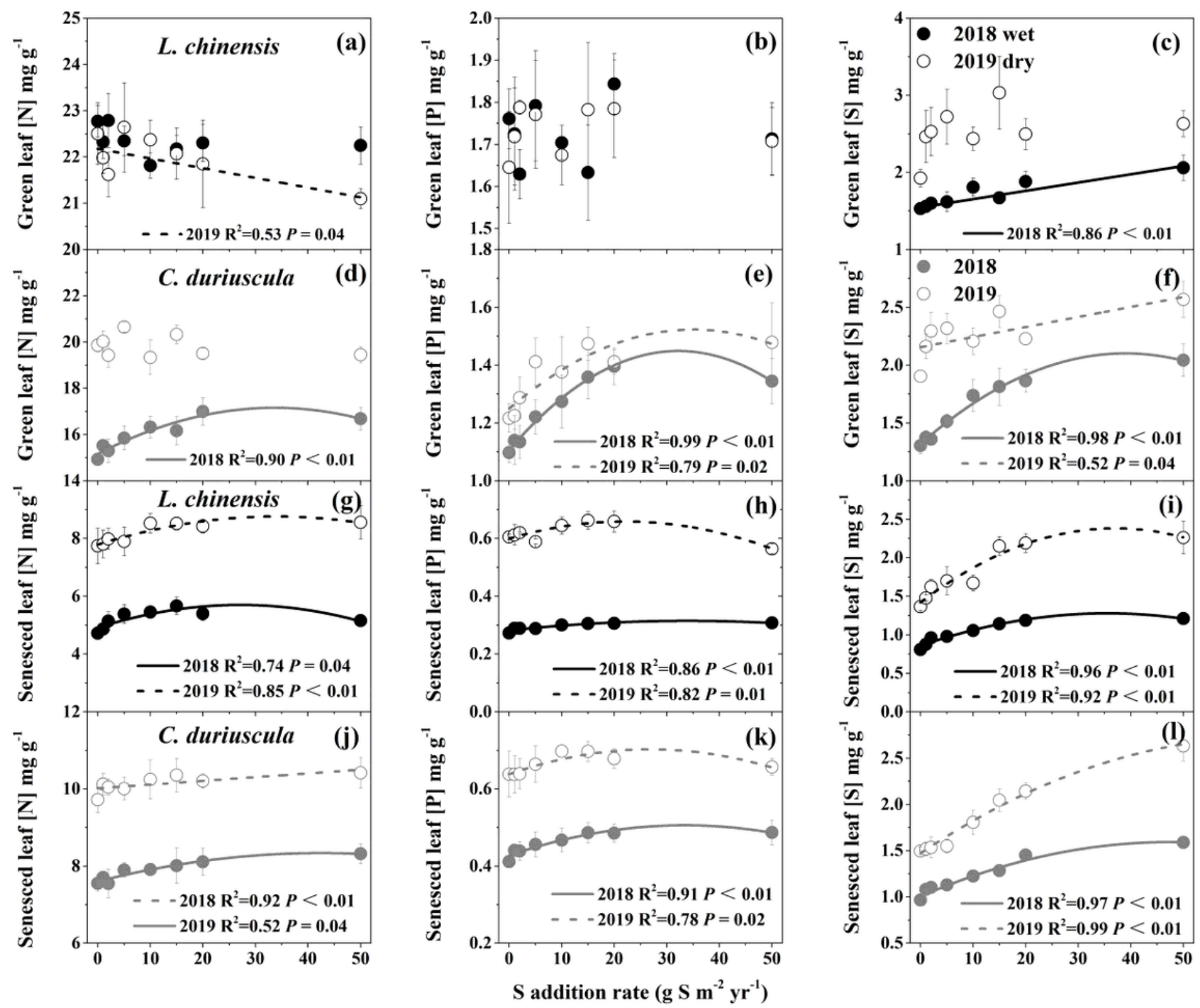

\section{Figure 1}

Changes in nutrient (N, P, and S) concentrations of green and senescent leaves with S addition for two dominant species in 2018 and 2019 in the meadow grassland. Error bars show standard errors. 


\section{L. chinensis}
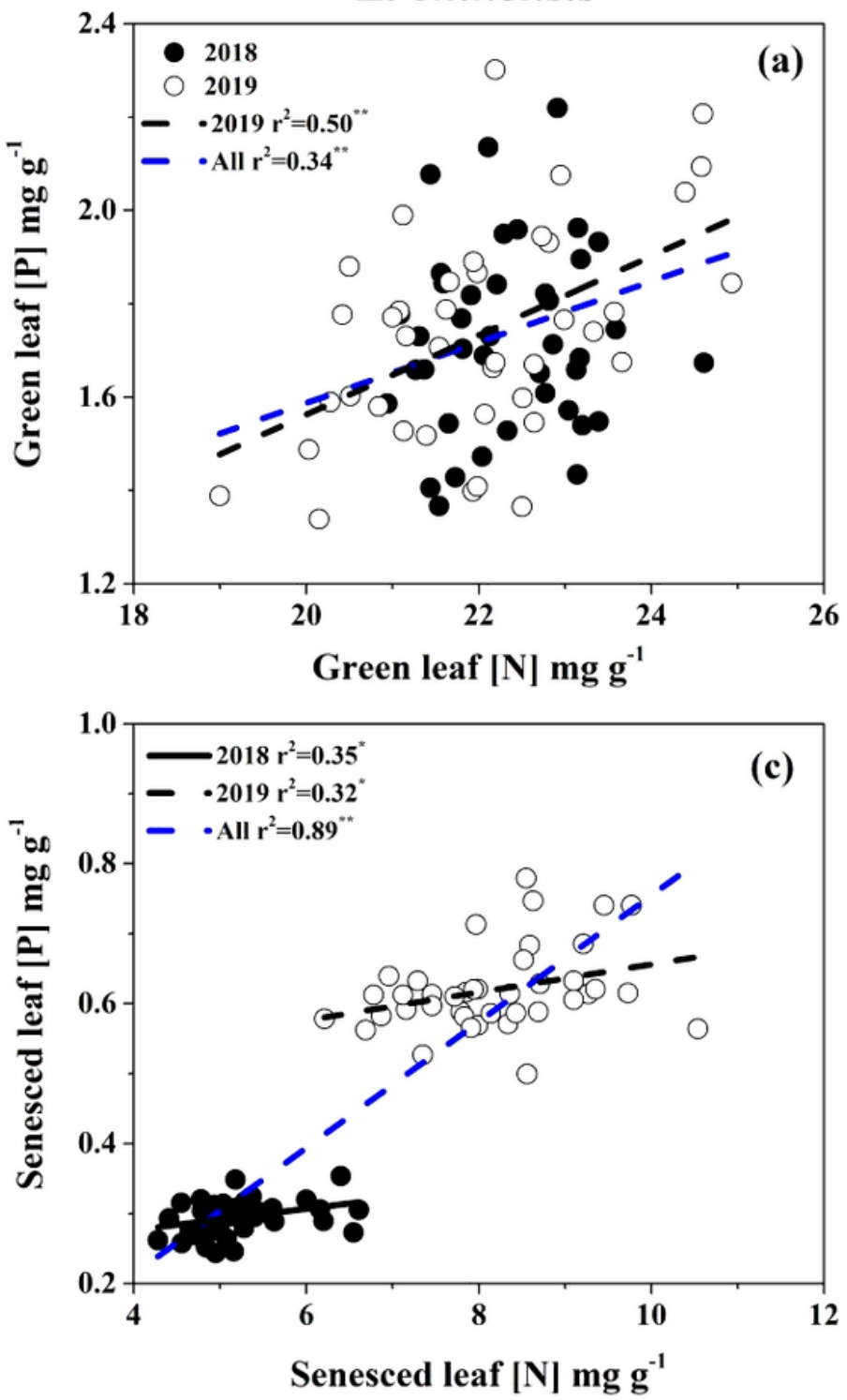

C. duriuscula
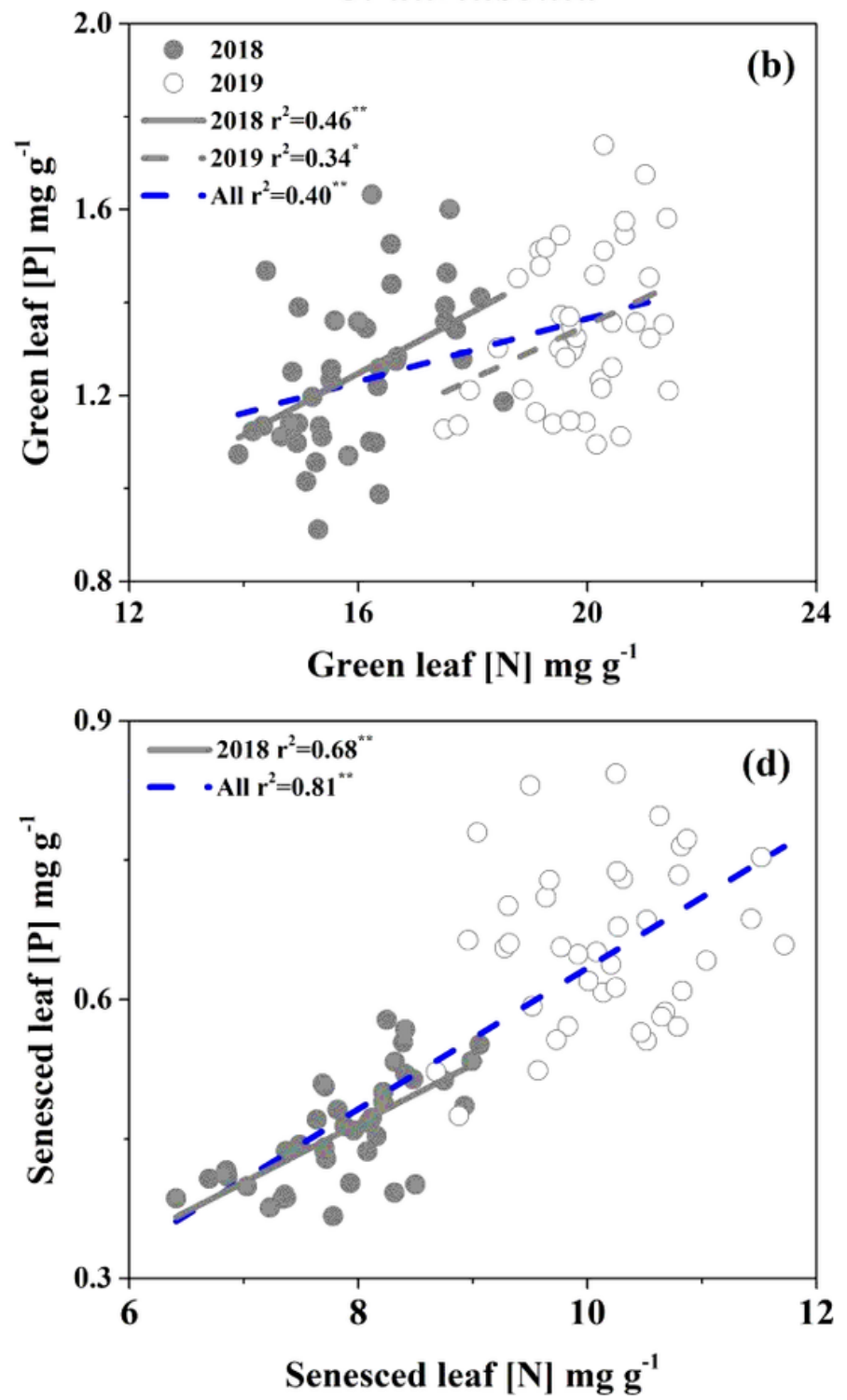

Figure 2

Relationships between $\mathrm{N}$ and $\mathrm{P}$ concentrations in green and senescent leaves. Correlation analyses were conducted across two years (blue-dashed lines) and separately for each year (solid lines for the wet year 2018 and dashed lines for the dry year 2019). * and ** represent $\mathrm{P}<0.05$ and 0.01 , respectively. 

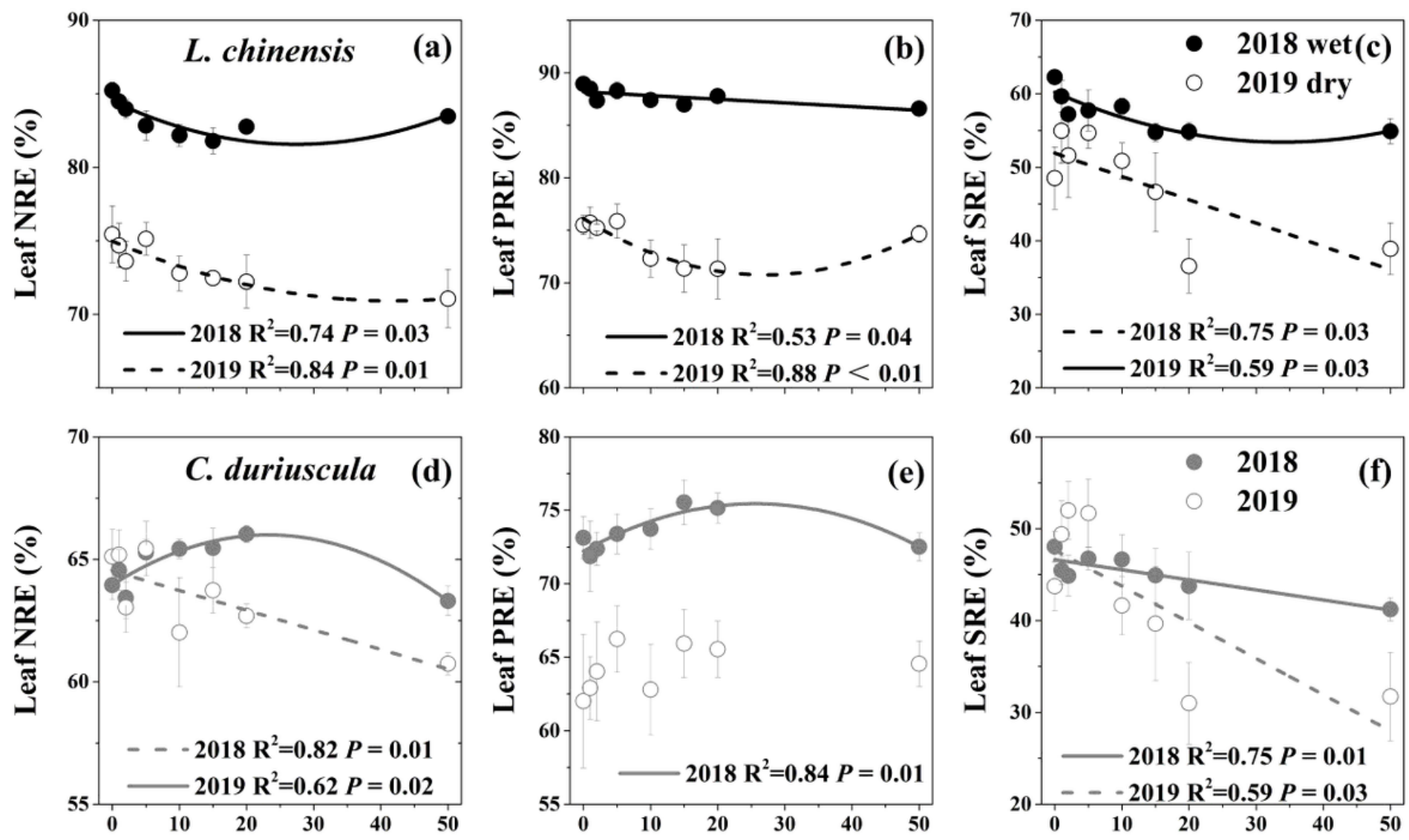

\section{$\mathrm{S}$ addition rate $\left(\mathrm{g} \mathrm{S} \mathrm{m}^{-2} \mathrm{yr}^{-1}\right)$}

Figure 3

Changes in nutrient resorption efficiency with S addition rates for two dominant species in 2018 and 2019 in the meadow grassland. Error bars show standard errors of the means. 


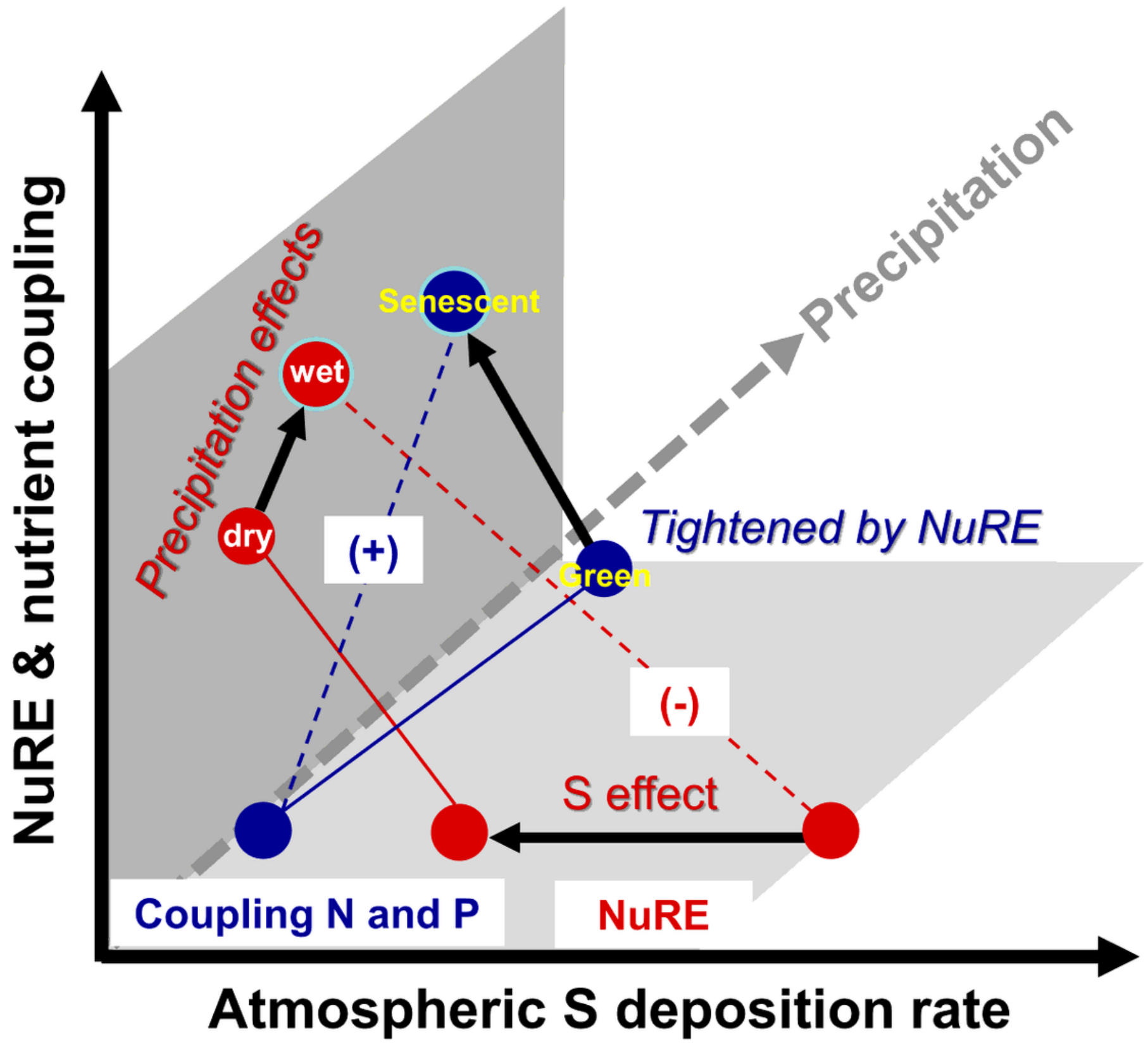

Figure 4

A multidimensional framework of the effects of sulfur $(\mathrm{S})$ deposition on coupling of nitrogen $(\mathrm{N})$ and phosphorus ( $P$ ) and nutrient (i.e., N, P, and S) resorption efficiency (NuRE) as mediated by precipitation. Positive coupling relationships between $\mathrm{N}$ and $\mathrm{P}$ were tightened by nutrient resorption process, as shown by blue dots with plus symbol ' + ' showing positive relationships. NuRE decreased with increasing $S$ addition rates as shown by red dots with a minus symbol '-' showing negative relationships. NuRE was higher in the wet year but showing a sharper decrease with S-addition rates in the dry year.

\section{Supplementary Files}


This is a list of supplementary files associated with this preprint. Click to download.

- Fengetal.Supplementarymaterial.docx 